\title{
EDUCAÇÃO EMANCIPATÓRIA COMO PEDRA ANGULAR PARA PROMOÇÃO, PROTEÇÃO E VALORIZAÇÃO DOS DIREITOS HUMANOS
}

\author{
Thiago Santos de Souza ${ }^{1}$ \\ Lívia Gabriela Fonseca Melo ${ }^{2}$ \\ Diego Bruno Souza Pires ${ }^{3}$
}

\section{RESUMO}

Este estudo tem como propósito, por meio de uma leitura conjunta de Jacques Rancière e Paulo Freire, o entendimento acerca da educação, com viés emancipatório, para a formação democrática dos sujeitos, visando à busca por promoção, proteção e valorização dos Direitos Humanos. Inicialmente, faz-se uma reflexão acerca da não hierarquia de inteligências e na crença da igual capacidade intelectual dos sujeitos e, em seguida, analisa-se o ensino tradicional e a proposta de uma educação emancipatória, refletindo sobre os objetivos intrínsecos daquela na manutenção da "cultura do silêncio", e desta, que se orienta no sentido da humanização. No terceiro momento, desenvolve-se a respeito da educação como um direito humano ao considerar a prática educativa como essencial na formação do conjunto de valores que fundamentam o reconhecimento de direitos e deveres. Ao final, discute-se acerca da importância da educação com vistas a ampliar a capacidade dos sujeitos na construção de uma consciência crítico-reflexiva, o que

\footnotetext{
Mestre em Saúde Comunitária pelo Instituto de Saúde Coletiva da Universidade Federal da Bahia (ISC/UFBA). Docente da Escola Bahiana de Medicina e Saúde Pública. ORCID: https://orcid.org/0000-0003-1427-7345.E-mail: thiago_fst@yahoo.com.br

2 Fisioterapeuta pela Universidade Tiradentes (UNIT). Docente da Faculdade Estácio Feira de Santana. Graduanda em Direito pela Universidade Salvador (UNIFACS). ORCID: https://orcid.org/0000-0002-4121-975X .E-mail: liviagabrielafm@gmail.com

3 Mestre em Educação pela Universidade Estadual de Feira de Santana (UEFS). Docente da Universidade Salvador (UNIFACS). Presidente da Comissão de Direitos Humanos da Ordem dos Advogados do Brasil - OAB de Feira de Santana/BA. ORCID: https://orcid.org/0000-0001-8180-7209. mail: consultoriasouzapires@gmail.com
} 
inclui a capacidade de se indignar e de resistir contra injustiças e no poder de decidir sobre questões que lhes dizem respeito, assim como nos processos de transformação e construção de uma sociedade mais democrática e humanizada.

Palavras-chave: Educação. Direitos Humanos. Democracia.

\section{EMANCIPATORY EDUCATION AS A CORNERSTONE FOR THE PROMOTION, PROTECTION AND APPRECIATION OF HUMAN RIGHTS}

\section{ABSTRACT}

This study aims, through a joint reading of Jacques Rancière and Paulo Freire, to understand emancipatory education for the democratic formation of subjects, in view of the search for promotion, protection and appreciation of Human Rights. Initially, a reflection is made about the non-hierarchy of intelligences and the belief of the equal intellectual capacity of the subjects, and then we analyze traditional teaching and the proposal of an emancipatory education, reflecting on the intrinsic goals of the first in maintaining a "culture of silence", and of the latter, which is oriented towards humanization. In a third stage, it develops on education as a human right by considering the educational practice as essential in the formation of the set of values that underlie the recognition of rights and duties. In the end, it discusses the importance of education in order to expand the ability of subjects to build a critical-reflective awareness, including the ability to be outraged and resist injustice, and to decide on issues that concern them, as well as in the processes of transformation and construction of a more democratic and humanized society.

Keywords: Education. Human Rights. Democracy. 


\section{EDUCACIÓN EMANCIPATORIA COMO ESQUINA PARA PROMOCIÓN, PROTECCIÓN Y APRECIACIÓNDE LOS DERECHOS HUMANOS}

\section{RESUMEN}

Este estudio tiene como objetivo, a través de una lectura conjunta de Jacques Rancière y Paulo Freire, la comprensión de la educación con un sesgo emancipatorio, para la formación democrática de los sujetos, en vista de la búsqueda de la promoción, la protección y la apreciación de los derechos humanos. Inicialmente, se hace una reflexión sobre la no jerarquía de las inteligencias y la creencia en la capacidad intelectual igual de los sujetos, y luego, analiza la enseñanza tradicional y la propuesta de una educación emancipadora, reflexionando sobre los objetivos intrínsecos de eso en el mantenimiento de la "cultura de silencio", y de esto, que está orientado hacia la humanización. En el tercer momento, se desarrolla sobre la educación como un derecho humano cuando se considera que la práctica educativa es esencial para formar el conjunto de valores que subyacen al reconocimiento de los derechos y deberes. Al final, discute la importancia de la educación con el fin de expandir la capacidad de los sujetos en la construcción de una conciencia crítico-reflexiva, que incluye la capacidad de indignarse y resistir contra las injusticias, y el poder de decidir sobre cuestiones que les dicen respeto, así como en los procesos de transformación y construcción de una sociedad más democrática y humanizada.

Palabras clave: Educación. Derechos humanos. Democracia.

\section{INTRODUÇÃO}

Este artigo tem como propósito desenvolver o entendimento acerca da educação com vistas à emancipação intelectual dos sujeitos para constituição da cidadania e para a promoção dos Direitos Humanos (DH). Para tanto, foi utilizado como referencial teórico o livro de Jacques Rancière $O$ mestre ignorante: cinco lições sobre a emancipação intelectual (2018), que reflete a respeito da 
emancipação intelectual do sujeito e o lugar da educação nessa missão. Associou-se $O$ mestre ignorante à proposta educativopedagógica de Paulo Freire.

O foco da análise, portanto, é fornecer elementos para desenvolver uma reflexão sobre a educação como instrumento no processo de construção do conhecimento e na formação de uma consciência crítico-reflexiva, fundamentando-se no princípio da igualdade, o que perpassa as relações de poder que envolvem a formação da subjetividade e permite que o sujeito seja capaz de se reconhecer como agente ativo na construção de uma democracia ativa e possa, após isso, contribuir com a valorização, com o fortalecimento e com a busca por efetividade dos $\mathrm{DH}$. Dito isso, não é de surpreender que tal proposta encontre uma ressonância direta com a pedagogia desenvolvida por Paulo Freire, que via, na educação, uma capacidade emancipadora, redefinindo a compreensão do que seria um processo de formação para a autonomia dentro dos quadros históricos de uma sociedade marcada pela desigualdade (GIMBO, 2017).

O livro de Jacques Rancière (2018) conta a história de Joseph Jacotot, um filósofo e educador francês que, enquanto estava exilado nos Países Baixos, em 1818, lecionou na Universidade de Louvain e, durante esse período, criou o método denominado por ele de Ensino Universal. Este ensino prevê que todo homem é capaz de instruir-se a si mesmo, bastando, para isso, que se emancipe intelectualmente. Essa proposta pedagógica prioriza a aprendizagem sem a explicação de um professor, e o seu princípio estabelece que, durante o processo da aprendizagem, há relações e conexões com conhecimentos anteriores, por meio dos princípios de seleção, progressão e incompletude (RODRIGUES, 2016). No livro referido, Jacques Rancière assevera que não existe hierarquia de inteligências, ou seja, não há uma inteligência superior e outra inferior, uma vez que "[...] não há ignorante que não saiba uma infinidade de coisas, e é sobre este saber, sobre esta capacidade em ato que todo ensino deve se fundar" (RANCIÈRE, 2018, p. 11). 
De acordo com Bretas (2017, n.p., grifo nosso):

Emancipar-se significa entender que há em todas as
pessoas uma igualdade de inteligências, além de
acreditar que toda e qualquer produção
artística/intelectual humana pode ser
compreendida por qualquer pessoa, sem a
necessidade de explicações para além de seu
próprio conteúdo.

A pedagogia apresentada por Rancière parte do princípio de que a igualdade é o ponto de partida, e não o objetivo final do processo educativo; ao passo que a educação tradicional é assentada na relação entre um mestre explicador, detentor do conhecimento, e um aluno ignorante que lhe é submisso e, por ocupar uma posição inferior, deve-lhe obediência (AQUINO, 1996). É justamente essa distância na relação hierárquica entre o mestre e o aluno que o ensino universal pretende reduzir.

No livro, há uma crítica ao sistema tradicional de ensino - que ele chama simplesmente de o Velho - uma vez que esse método não conduz ao conhecimento, posto que o aluno depende da explicação do professor e só a partir disso que ele vai progressivamente "[...] compreender que nada compreenderá, a menos que lhe expliquem" (RANCIERE, 2018, p. 21), o que ele designou de embrutecimento. Desse modo, um sempre está na dependência do outro; o mestre explicador precisa do ignorante para transmitir o seu saber, e o ignorante está sempre à espera da explicação, daquele que irá Ihe abrir as portas para o conhecimento, o que resulta em um indivíduo que não pensa com suas próprias faculdades mentais, com sua própria inteligência, e só leva ao aluno a certeza de que quem sabe é o professor, e que o educando só saberá o que lhe for explicado. É a absolutização da ignorância que constitui o que se chama de alienação (FREIRE, 2005). Aliena-se a inteligência do aluno à inteligência do professor.

Rancière parte do pressuposto de que não há desigualdade de inteligências, mas, sim, uma desigualdade nas manifestações dessas inteligências. A inteligência é atenção e busca antes de ser combinação de ideias, uma vez que depende da vontade que 
comunica à inteligência para descobrir e combinar relações novas. A vontade é a potência de se mover, de agir segundo movimento próprio, antes de ser instância de escolha (RANCIÈRE, 2018). Nessa vertente, o desenvolvimento da inteligência pode ser visto como uma associação entre a vontade e o poder racional, e, conforme anunciado por Freire (2005, p. 101) "[...] o momento deste buscar é que inaugura o diálogo da educação como prática de liberdade".

É a vontade de aprender e de procurar incessantemente, por iniciativa própria, que confere significado às coisas. Essa racionalidade, guiada pela vontade, gera a verdade. Para Rancière, 0 princípio da veracidade resulta da experiência da emancipação. No processo de emancipação, o homem aproxima-se da verdade, pois a "[...] verdade existe por si mesma; ela é o que é e não o que é dito [...]" (RANCIERE, 2018, p. 68).

Uma crítica precisa ser feita aqui. Pensar que somente a vontade é suficiente para guiar o processo de construção do conhecimento é não levar em consideração que a posição social que o indivíduo ocupa tem influência direta sobre a sua formação, já que a inteligência de um pode ser mais desenvolvida que outra, em determinada esfera de convivência individual, devido às ocasiões em que essa fora exposta. Assim, não há uma relação superior e inferior entre elas, mas há uma atenção voltada para os seus respectivos campos de interesses e circunstâncias.

A sociedade, por sua vez, sustenta-se nessa convenção, na hierarquização de inteligências e, como consequência, na paixão pela desigualdade em todos os sentidos, perpetuando-a. O progresso pela educação aponta a escola como reprodutora das desigualdades sociais visto que ela funda e justifica os programas de educação do povo e, em última análise, a própria dinâmica social, permanecendo, segundo Rancière, presa à redução das desigualdades presentes em nome de uma igualdade futura.

A distância que a Escola e a sociedade pedagogizada pretendem reduzir é aquela de que vivem e que não cessam de reproduzir [...]. A própria desigualdade social já a supõe: aquele que obedece a uma ordem deve, primeiramente, compreender a 
ordem dada e, em seguida, compreender que deve obedecê-la (RANCIÈRE, 2018, p. 11)

Rancière ressalta que a educação propõe, de um lado, a redução da desigualdade pela explicação das regras do jogo e pela racionalização das formas de aprendizagem e, de outro, enuncia implicitamente a irrelevância de qualquer reforma, fazendo dessa violência simbólica um processo que reproduz indefinidamente suas próprias condições de existência (RANCIÈRE, 2018).

Nessa perspectiva, faz-se necessário que o sujeito busque o todo da inteligência humana em cada manifestação para que possa perceber-se como um ser integrante e participativo no seu contexto social. É pela educação que o indivíduo tem a possibilidade de interagir com seus pares, o que o permite desenvolver a capacidade para transformação de sua realidade. "A educação precisa despertar o cidadão que está em cada estudante para que contribuam no exercício de suas competências para a garantia e promoção dos Direitos Humanos" (VALDAMERI, n.p., 2018). A luta pelos DH passa por questões concretas que pressupõem o desenvolvimento de um compromisso individual e coletivo com a promoção desses direitos, o que passa obrigatoriamente pela educação.

O progresso é a nova maneira de dizer a desigualdade, uma vez que um homem de progresso é aquele que erige essa opinião à condição de explicação dominante da ordem social. Como já foi visto, a explicação não é somente um instrumento embrutecedor dos pedagogos, mas "[...] o próprio laço da ordem social" (RANCIÈRE, 2018, p. 162).

A respeito disso, Paulo Freire (2001, p. 27) destaca:

Às vezes, a violência dos opressores e sua dominação se fazem tão profundas que geram em grandes setores das classes populares a elas submetidas uma espécie de cansaço existencial que, por sua vez, está associado ou se alonga no que venho chamando de anestesia histórica [...]. Daí a necessidade da intervenção competente e democrática do educador nas situações dramáticas em que os grupos populares, demitidos da vida, estão como se tivessem perdido o seu endereço no 
mundo. Explorados e oprimidos a tal ponto que até a identidade Ihes foi expropriada.

Ainda de acordo com o mesmo autor, "[...] um elitista compreende a expressão como uma prática educativa centrando-se em valores das elites e na negação implícita dos valores populares" (FREIRE, 2001, p. 23). Para que haja uma democracia plena, é necessário que o indivíduo seja emancipado intelectualmente e possa, a partir disso, buscar a efetivação dos seus direitos e deveres com a real liberdade advinda da democracia, ou seja, para que possa exercer sua inteligência sem a interferência dos preceitos que inserem na mente humana a falsa ideia de desigualdade intelectual e superioridade de inteligências, pois, como explicitado por Rancière (2018, p. 64): "[...] o que embrutece o povo não é a falta de instrução, mas a crença na inferioridade de sua inteligência".

A busca pela emancipação intelectual faz-se fundamental no exercício da democracia e no reconhecimento de que o indivíduo é um ser social; sendo assim, a análise da obra de Rancière e da proposta pedagógica de Paulo Freire contribui para ampliar a compressão acerca do desenvolvimento da educação na formação do sujeito, tendo em vista a sua emancipação, e consequente humanização, o que justifica a relevância do estudo e a discussão de suas ideias. Ademais, sobretudo, colabora para uma educação críticoproblematizadora e para a construção de uma cultura para a vivência dos $\mathrm{DH}$ que busca promover, proteger e valorizar tais direitos.

Para tanto, a análise temática se desenha inicialmente se alicerçando sobre o reconhecimento acerca da não hierarquia de inteligências e na crença da igual capacidade intelectual dos sujeitos. Em seguida, analisam-se o ensino tradicional e a proposta de uma educação emancipatória, refletindo sobre os objetivos intrínsecos daquela na manutenção da "cultura do silêncio", e desta, que se orienta no sentido da humanização. No terceiro momento, desenvolve-se a respeito da educação como um direito humano ao considerar a prática educativa como essencial na formação do conjunto de valores que fundamentam o reconhecimento de direitos e deveres. Ao final, discute-se acerca da importância da educação com vistas a ampliar a capacidade dos sujeitos no poder de decidir sobre questões que lhes dizem respeito, assim como nos processos 
de transformação e construção de uma sociedade mais democrática e humanizada.

\section{IGUALDADE DA CAPACIDADE INTELECTUAL (não existência da hierarquia das inteligências)}

Não existe uma inteligência superior ou inferior, isso permite o princípio da igualdade e "[...] é a tomada de consciência dessa igualdade que se chama emancipação e que abre o caminho para toda a aventura no caminho do saber" (RANCIÈRE, 2018, p. 49). A frase enuncia o princípio fundamental da educação e o reconhecimento da inteligência como potência de conhecer, o que é comum a todos os seres humanos, visto que não há um único sujeito humano que nunca tenha aprendido nada. Portanto, conhecer é uma capacidade essencial e intrínseca à vida humana, uma atividade fundante por meio da qual nos relacionamos e mediamos nosso ser com o mundo (GIMBO, 2017).

É precisar deixar claro, neste ponto, que analisar a igualdade entre inteligências não é homogeneizar as pessoas, mas partir do princípio de que se deve respeitar o direito de desenvolvimento singular, ou seja, constitui-se de uma multiplicidade de inteligências, e não no idêntico, "[...] por isso, a igualdade é a antítese do desigual, não da diferença" (GIMBO, 2017, p. 273), pois é evidente que os sujeitos possuem aptidões e competências diferentes; porém, todo e qualquer homem é capaz de ocupar qualquer posição e de realizar qualquer tarefa desde que ele tenha a chance para tanto. O que há é uma capacidade universal igual (FERRARI, 2014) e, segundo Rancière (2018, p. 50), "O problema está revelar uma inteligência a ela mesma". Ainda na mesma obra, ele ressalta (p. 66):

A crença na desigualdade intelectual e na superioridade de sua própria inteligência não é, em nada, uma exclusividade dos sábios [...]. Assim vai a crença na desigualdade. Não há espírito superior que não encontre um mais superior ainda para rebaixá-lo; não há inferior que não encontre outro mais inferior ainda, para desprezar. 
A crença na inferioridade da inteligência é também apontada por Paulo Freire, que a chamou de autodesvalia, e a define como sendo o resultado da introjeção que os oprimidos fazem da visão que os opressores têm deles, pois "[...] de tanto ouvirem de si mesmos que são incapazes, que não sabem nada, que não produzem em virtude disso, terminam por se convencer de sua incapacidade" (FREIRE, 2005, p. 56, grifos do autor)

Essa hierarquização social é que dá subsídio para a desigualdade e é reforçada pelos próprios sujeitos que se dizem inferiores ao renunciarem o seu próprio potencial de aprender, de questionar, em detrimento da sua permanência na impotência de pensar (HIDALGO; ZANATTAS; FREITAS, 2015). Para o homem, existe o cômodo de não pensar, de se achar insuficiente, pois nunca o deixaram tentar, e é inútil discutir se sua inteligência "menor" é um efeito da natureza ou da sociedade, pois, conforme apontado por Rancière (2018), o sujeito desenvolve a inteligência que suas necessidades e circunstâncias exigem.

Sendo assim, há certa dificuldade em conseguir alcançar a emancipação; e, por isso, poucos são emancipados. No entanto, uma vez emancipado, o indivíduo pode emancipar outro e assim por diante. Como afirma Rancière (2018, p. 47) "Na ordem intelectual, podemos tudo o que pode um homem". Na mesma obra, o autor ainda pontua que a distância que o ignorante precisa transpor não é o abismo entre a sua ignorância e o saber do mestre, mas o caminho que vai entre o que ele sabe e o que ele ignora.

Nesse contexto, a sociedade é marcada pelas relações de desigualdades e pela divisão social de classes, e atribui ao ensino a tarefa de instruir, que, em outras palavras, seria um meio de "[...] instituir algumas mediações entre o alto e o baixo: um meio de conceder aos pobres a possibilidade de melhorar individualmente sua condição e de dar a todos o sentimento de pertencer, cada um no seu lugar, a uma mesma comunidade" (RANCIERE, 2018, p. 14, grifos do autor). $O$ autor salienta ainda que quem estabelece

[...] a igualdade como objetivo a ser atingido, a partir da situação de desigualdade, de fato a posterga até o infinito. A igualdade jamais vem após, como 
resultado a ser atingido. Ela deve ser sempre colocada antes. (RANCIERE, 2018, p. 11).

Assim, a igualdade não é uma finalidade, ela é o ponto principal do princípio da emancipação intelectual, ela é a pressuposição de que "É preciso pôr o suposto ignorante em uma situação onde a igualdade possa ser maximizada, onde ela possa ser tomada como ponto de partida, produzindo seu efeito" (VERMEREN; CORNU; BENVENUTO, 2003, p. 190). A ênfase, nesse caso, está em permitir que cada vida inteligente tenha seu direito ao pleno desenvolvimento, tal como Kant (2005 apud GIMBO, 2017), ao insistir que todos os homens, por meio do uso livre do seu próprio entendimento, são capazes de pensar por si e, consequentemente, tornarem-se igualmente livres.

Há sempre alguma coisa que o ignorante sabe e que pode servir de termo de comparação, ao qual é possível relacionar uma coisa nova a ser reconhecida (RANCIÈRE, 2018). Nessa vertente, Paulo Freire (2019, p. 139) cita um camponês que, após algumas aulas de alfabetização, disse: "Antes nós não sabíamos que sabíamos, agora sabemos que sabemos. Porque hoje sabemos que nós sabemos, podemos cada vez mais", e Rancière (2018, p. 57) alude que "[...] essa compressão é que se denomina de emancipação, e é se emancipando intelectualmente que o homem irá perceber que tudo pode, e que pode refletir sobre o que é e o que faz na ordem social".

Paulo Freire enfatiza a questão do saber em uma perspectiva emancipadora da educação que, desse modo, ganha força, inspirada na proposta de Jacotot, a afirmação da igual capacidade de pensar de todos os seres humanos como princípio de tal educação. Nesse norte, afirmar uma concepção igualitária da capacidade de pensar de mestres e alunos passa a ser uma condição política necessária para que os participantes dessa prática educativa possam desdobrar a igual potência problematizadora de que são capazes e colocar em questão um estado de coisas.

A igualdade das inteligências é o laço comum do gênero humano, a condição necessária e suficiente para que uma sociedade de homens exista (RANClÈRE, 2018). Sendo assim, a emancipação intelectual parece ser inequívoca em uma democracia que implica o 
reconhecimento e o respeito à singularidade de cada sujeito social em seu exercício de cidadania (FORTUNATO, 2019).

\section{EDUCAÇÃO TRADICIONAL (princípio explicador/ ordem explicadora) $X$ EDUCAÇÃO EMANCIPATÓRIA/ PROBLEMATIZADORA}

A Constituição Federal de 1988 (BRASIL, 1988) ostenta, em seu art. 205, o direito à educação, referindo este ser um

[...] direito de todos e dever do Estado e da família, e será promovida e incentivada com a colaboração da sociedade, visando ao pleno desenvolvimento da pessoa, seu preparo para o exercício da cidadania e sua qualificação para o trabalho.

Além de reconhecer, no art. $208, \S 1^{\circ}$, a educação como um direito público subjetivo, sendo "[...] aquele pelo qual o titular de um direito pode exigir direta e imediatamente do Estado o cumprimento de um dever e de uma obrigação", e social de ordem fundamental, o que o vincula a uma prestação positiva do Estado com promoção de políticas públicas que visam garantir a sua eficácia conforme disposto no art. $6^{\circ}$ do mesmo diploma. A Magna Carta também reconhece, no art. $5^{\circ}, \S 1^{\circ}$, que a educação é um direito pleno de aplicação imediata (BRASIL, 1988).

A educação ora é um instrumento, ora é um processo pelo qual o indivíduo utiliza a sua inteligência para expressar-se em sociedade, dentro da sua cultura, em linha de aprendizagem e aperfeiçoamento, sendo a maneira pela qual as pessoas se capacitam para a vida. É pela educação que o homem tem a possibilidade de desenvolver-se individualmente (PIRES, 2017; DALLARI, 1998), e passa a ser entendido como produto e produtor da cultura e da vida social.

Todavia, hodiernamente, os processos educacionais formais são sustentados na relação vertical entre o professor e o aluno; e, nessa configuração, o primeiro possui a centralidade do processo educacional, enquanto o segundo, conforme definido por Freire (2005), é posto como uma "vasilha vazia" à espera para ser preenchida 
pelos conhecimentos do professor. O mestre é uma autoridade que deve ser respeitada e obedecida pelo aluno, que ocupa uma posição inferior. Além disso, o docente manifesta a sua superioridade diante do que o aluno pensa ter compreendido e o deixa mantendo sua ignorância, o não saber, mantendo-o sempre submisso a uma explicação (RANCIÈRE, 2018).

É preciso uma explicação para que o aluno seja capaz de aprender, seguido de um princípio, que é a desigualdade das inteligências. Por essa repartição de inteligências é que o mundo é dividido entre sábios e ignorantes, sendo necessário que alguém com uma inteligência elevada auxilie os "menos" inteligentes a deixar o estado de ignorância.

Diante disso, o mestre leva o conteúdo a ser estudado, o livro, mas o aluno não toma conhecimento dele, e quando o compreende é por meio da interpretação do mestre, como se o livro necessitasse de uma voz para ser aprendido. Nessa senda, compreender denotase como a apreensão passiva de algo dado, contrário do aprender que exige um esforço que lhe é recompensado com aptidão. Para Rancière (2018, p. 21), "[...] a lógica da explicação comporta, assim, o princípio de uma regressão ao infinito", que é a lógica do nosso sistema de ensino, em que a explicação é consequência de uma compreensão, e compreender é o que o aluno não pode fazer sem as explicações fornecidas, em certa ordem progressiva, por um mestre.

O importante seria o aluno desmembrar o livro, para entender o aprendizado complexo que ele traz, e o mestre apenas seria um auxílio de dúvida, como pode ser visto na citação:

O livro é uma fuga bloqueada: não se sabe que caminho traçará o aluno, mas sabe-se de onde ele não sairá - do exercício de sua liberdade. Sabe-se, ainda, que o mestre não terá o direito de se manter longe, mas à sua porta. (RANCIÈRE, 2018, p. 44).

Não pode haver conhecimento uma vez que os educandos não são chamados a conhecer, mas a memorizar o conteúdo. Paulo Freire apresenta que, nessa prática pedagógica, os educandos são como "vasilhas" ou depósitos de conteúdos a serem "enchidos" pelos educadores, cujo objetivo é a distribuição universal e igualitária do 
saber sob o escopo de promover igualdade social, ou ao menos de reduzir a "fratura social", porém essa proposta apresenta uma contradição traiçoeira, pois ela mesma reconstitui indefinidamente a desigualdade que pretende suprimir, pois saber não comporta, por si só, qualquer consequência igualitária, havendo, nesse caso, ao invés de superação, manutenção da "cultura do silencio" (FREIRE, 2005, grifos do autor).

O princípio do embrutecimento, como denominado por Rancière, é exatamente o método explicativo. O mestre/educador mantém a postura de que seus alunos não têm capacidade de aprender; assim, não leva o aluno a compreender por si próprio sem as suas explicações e fornece cada vez mais explicações aprimoradas. "Há sempre uma distância a separar o mestre do aluno, que, para ir mais além, sempre ressentirá a necessidade de outro mestre, de explicações suplementares" (RANCIÈRE, 2018, p. 41). E esta é a virtude dos explicadores: "[...] o ser que inferiorizam, eles o amarram pelo mais sólido dos laços ao país do embrutecimento: a consciência de sua superioridade" (RANCIÈRE, 2018, p. 42).

Do modo explicativo, o aluno não tem fundamento do assunto, pois ele não faz parte daquilo que está sendo exposto se não o mestre e, desse modo, sendo de puro desinteresse de parte do discente por não se inteirar do assunto e apenas reter o que lhe é falado, pois irá ser cobrado. Desse modo, cabe ao estudante docilmente receber agradecido o pacote e memorizá-lo. Esse processo não leva em consideração o conhecimento de experiência feito com que o educando chega à escola, valorando apenas o saber acumulado, chamado científico, de que é possuidor. Tornar o aluno como objeto de prática educativa quando na verdade ele é um dos sujeitos.

Assim sendo, o educando é pura incidência de sua ação de ensinar (FREIRE, 2001); e, nesse processo, o educador transmite uma hierarquia que é incompatível com a liberdade e só contribui para perpetuar, entre os alunos, a sensação de inferioridade (MULINARI; MUNIZ, 2018). O professor assume na íntegra seu papel de narrador, e os alunos, de ouvintes, com pouco espaço para o diálogo e para a reflexão, o que inibe a criatividade e domestica a consciência, além de implicar uma espécie de anestesia, tornando-os extremamente 
passivos - e, para a sociedade opressora, é essencial que tal prática fortaleça essa situação e mantenha o que Paulo Freire apresenta como "imersão das consciências".

A noção de emancipação intelectual, proposta por Rancière, em oposição ao embrutecimento, tem como pressuposto a igualdade das inteligências. Só existe saber na invenção, na reinvenção, na busca inquieta, impaciente e permanente. $\mathrm{Na}$ educação problematizadora (ou libertadora), o educador situa o aluno em experiências de saber em que se rompe a desigualdade das inteligências e hierarquia das posições. São experiências que não antecipam o que deve ser aprendido, mas potencializam sensibilidades em aprender algo novo para ambos e juntos (TRÓPIA; PINTO NETO, 2017). O ponto de partida da educação libertadora se caracteriza exatamente com essa dimensão da relação do homem com a realidade em que vive pelo fato de que o processo educacional deve ser a partir da realidade dos educandos, e não a partir das ideias do professor.

Essa proposta de educação possui como pressupostos aspectos totalmente contrários aos da educação explicadora. O princípio da emancipação intelectual é oposto ao do embrutecimento, e parte da suposição da igualdade das inteligências, a qual não é um objetivo a ser alcançado, mas é o meio para aprender. Ou seja, não existe mais divisão entre os sábios e ignorantes, e, sim, o uso da sua inteligência, pois com ela todo homem pode alcançar seus objetivos. Desse modo, o mestre deve ser apenas um mediador da aprendizagem, um facilitador.

Entretanto, para emancipar outrem, é preciso, inicialmente, emancipar-se a si próprio. Em outras palavras, é preciso perceber-se tanto como um ser de conhecimento quanto como um ser inacabado, pois, ao educar o aluno, o educador também aprende, ou seja, esse diálogo confere, a ambos, experiências únicas de aprendizado (FREIRE, 2005) - e, ao emancipar-se intelectualmente, o indivíduo adquire a capacidade de refletir "[...] sobre o que é e o que faz na ordem social" (ENSEIGNEMENT UNIVERSAL, 1836 apud RANCIERE, 2018, p. 57).

Por fim, o método da emancipação é mostrar a necessidade, a importância e a utilidade de levar a pensar de forma autêntica para o pensamento crítico. $O$ indivíduo que educa a si mesmo amplia sua 
visão de mundo, aumenta sua percepção e linguagem, carregando, assim, um conhecimento imenso. O mestre deve acreditar na capacidade do aluno, incentivar o seu aperfeiçoamento, e não priorizar as explicações. Com isso, desenvolvem-se os valores físicos, intelectuais e morais, permite-se construir uma igualdade justa dentro da sociedade.

O princípio da desigualdade das inteligências, orientador da educação tradicional, é um dos obstáculos mais sérios à emancipação, pois se caracteriza por uma ausência de diálogo que desencadeia uma reprodução da opressão e da violação dos $\mathrm{DH}$. Já uma educação que procura desenvolver uma tomada de consciência e uma atitude crítica, que permite ao homem escolhas, liberta-o em lugar de submetê-lo, e é uma educação que tende a preparar o indivíduo à sociedade e que, de algum modo, o incentiva a desenvolver e utilizar seu potencial intelectual, como meio para construir sua cidadania existencial (FORTUNATO, 2019; FREIRE, 1979).

Ao conceber a instrução pública como condição para promover emancipação intelectual, Rancière chamou atenção para a necessidade de inverter a lógica da explicação como fundamento do processo educacional que negligencia a capacidade dos homens de aprenderem por si sós, sendo este o maior desafio do ensino universal que é fazer com que aqueles que se julgam inferiores em inteligência saiam da obscuridade em que vivem, orientem-se na compreensão do mundo e tornem-se participantes ativos enquanto sujeitos de transformação (HIDALGO; ZANATTAS; FREITAS, 2015). Ou seja, a formação, enquanto prática educativa, precisa libertar-se do princípio explicador como ato pedagógico que impossibilita o pensamento crítico-reflexivo reconhecer a sua eficácia como alavanca da transformação profunda da sociedade. O processo educacional não pode se tornar um instrumento ideológico que anule a capacidade do indivíduo de perceber e criticar a sua realidade social, pois, segundo Freire (2001), somente uma educação séria, rigorosa, democrática, e em nada discriminatória, pode ser desveladora das verdades, desocultadora e iluminadora das tramas sociais e históricas. 


\section{EDUCAÇÃO COMO UM DIREITO HUMANO}

A educação é o conjunto de métodos que asseguram a formação intelectual e moral do ser humano, sendo, portanto, resultado da ação humana. "O direito à educação ou a instrução foi um direito garantindo ainda no decorrer do século XVIII" (BEDIN, 2002, p. 71), e tem o seu acesso determinado livremente por cada país conforme seu plano nacional. Entretanto, a constituição, ou não, do indivíduo ocorre segundo as necessidades da sociedade e na manutenção da existência de estruturas históricas de desigualdade de poderes.

A educação formal é estipulada por homens que se legitimaram socialmente, em um círculo de poder que proíbe cada qual de fazer o que quer, somente reconhecendo os sujeitos pela função que Ihes foi socialmente determinada. Foi definido o papel de cada indivíduo, ou seja, cada um está adequado à medida de sua capacidade (MULINARI; MUNIZ, 2018, p. 73, grifo nosso).

Nesse sentido, a sociedade é regida pelo progresso da dominação, em todas as suas formas, e esse progresso técnicomaterial é utilizado com o intuito de produzir mais desigualdade. $\mathrm{O}$ processo educacional é desenvolvido com vistas a produzir aquilo que interessa ao mercado, e não o progresso moral; e a ausência deste vai impactar fortemente sobre o modelo de construção histórica dominante (SANTOS, 2000).

A educação, de acordo com Gadotti (2007, p. 12 apud VALDAMERI, 2018, n.p.), é "[...] ao mesmo tempo, fator e produto da sociedade". Os educadores já chegam com suas aulas prontas, e seus conteúdos montados e esquematizados, sem se preocupar com o que os educandos já sabem e como sabem. A eles, não interessa saber qual a linguagem de mundo dos alunos, mas, sim, o que estes devem conhecer, conforme referido por Freire (2001, p. 30), "o que conhecemos e da forma como conhecemos. E quando assim nos comportamos, prática e teoricamente, somos autoritários, elitistas, reacionários". Dessa forma, aniquilam-se os sentidos, marginalizam- 
se as sensações e criam-se distanciamentos entre a teoria debatida em sala de aula e a realidade existente fora dos muros escolares (AQUINO; DANELI, 2016).

A criança que começa sua instrução propriamente dita partindo de si mesma é encaminhada a uma instituição educacional, com modelos prontos; e, dessa forma, perde o seu recurso de usar sua própria inteligência para compreender e passa a assimilar os raciocínios interpretativos de um professor. A partir desse momento, já não pode questionar ou compreender sem as explicações fornecidas, em ordem progressiva, por um doutrinador (MULINARRI; MUNIZ, 2018).

Os $\mathrm{DH}$ foram construídos com base na ideia de dignidade da pessoa humana, ou seja, de que todo o ser humano, independentemente de qualquer condição pessoal, deve ser igualmente reconhecido e respeitado. O princípio democrático da educação resvala os preceitos de liberdade, igualdade e solidariedade, e dá embasamento para a construção das condições de acesso à educação e para a permanência ao direito educacional (BRASIL, 2013; MAGRI, 2012). Nesse sentido, Cunha (2014, p. 128, grifo nosso) preleciona:

Direitos humanos são direitos dos homens, não como regra decorrente de um sistema de imputação que, reagindo a influências históricas, prescrevem condutas e resguardam possibilidades, pondo-as ao abrigo da intervenção de terceiros. Inclusive do próprio Estado (liberdades públicas). Direitos Humanos são aqueles que, talvez independentemente de qualquer estatuição, guardam uma relação umbilical conosco mesmos. São inerentes à nossa própria condição humana porque resguardam nossas possibilidades existenciais, ou seja, existem para permitir que sejamos o que podemos ser. Alguns afirmam que são expressões de nossa dignidade, mas o que é dignidade humana? Este princípio e regido como marco fundacional dos direitos humanos, por isso mesmo é visto como um baluarte para os seus defensores. Kant o usou como critério distintivo do humano, ou seja, homem é aquele ente dotado de 
dignidade, que tem um valor em si mesmo e que, por isso, não deve ser usado de modo instrumental.

Pensar na educação sob a ótima dos $\mathrm{DH}$ requer libertar os cidadãos da escuridão em que habitam - e, como consequência, o saber lhes traz luz acerca da democracia, dos direitos e da sociedade. É uma educação permeada de cidadania, consubstanciada na releitura da sociedade, com formação voltada para as esferas humana, social e política. "A educação como obra libertadora do homem e do mundo e não como um ato individual de manipulação e de domínio" (GADOTTI, 1981, p. 155).

Nesse sentido, por exemplo, que temos que reconhecer que se, de um ponto de vista progressista, a prática educativa deve ser, coerentemente, um fazer desocultador de verdades e não ocultador, nem sempre o é do ponto de vista reacionário. E se o faz, o será de forma diferente. É que há formas antagônicas de ver a verdade - a dos dominantes e a dos dominados (FREIRE, 2001, p. 22).

Para que uma sociedade seja, de fato, democrática, há necessidade de informação e reconhecimento para que o indivíduo possa situar-se no mundo, argumentar e reivindicar, ou seja, nesse contexto, a educação com viés emancipatório tornará o sujeito mais consciente, dando-Ihe ferramentas para que ele possa sair da situação que o impede de reconhecer-se como um sujeito de direitos. Além disso, para que esse sujeito possa participar da formação de uma sociedade mais justa, esse processo deve priorizar o desenvolvimento da autonomia e da participação ativa, e permitir o empoderamento das pessoas como uma condição para a obtenção de acesso aos bens e para melhor compreensão de mundo e da dinâmica social.

Nessa senda, a transformação promoverá um processo de construção a partir da leitura crítica do mundo e dos espaços com que os indivíduos se relacionam e se reconhecem como sujeito de direitos e deveres e exercendo a solidariedade uns com os outros. Nessa dimensão, a educação em si é um direito humano, mas ao 
mesmo tempo possui expressiva contribuição para com os demais $\mathrm{DH}$ e, com isso, importante mecanismo de fortalecimento de práticas individuais e sociais que gerem ações e instrumentos em favor da promoção, da proteção e da defesa dos $\mathrm{DH}$, bem como da reparação das violações. Para Magendzo (2002), o respeito à dignidade humana deve permear as relações no tecido social, de forma que a vigência dos DH se materialize na democracia social, econômica e cultural.

\section{IMPORTÂNCIA DA EMANCIPAÇÃO INTELECTUAL PARA A VALORIZAÇÃO E FORTALECIMENTO DOS DIREITOS HUMANOS NA SOCIEDADE}

A discussão dos $\mathrm{DH}$ sob o contexto da educação faz-se extremamente relevante, pois, desde o preâmbulo da Declaração Universal dos Direitos Humanos, de 1948, aponta-se para a necessidade de "[...] empenhar-se por meio do ensino e da educação, em promover o respeito pelos direitos e liberdade" (ORGANIZAÇÃO DAS NAÇÕES UNIDAS, 1948); e, com isso, a educação é um mecanismo fundamental na promoção dos $\mathrm{DH}$ e para a construção de uma sociedade livre, justa e solidária. Nessa seara, estes são definidos como o conjunto de princípios que regem o convívio social e constituem-se de valores e concepções democráticas de respeito ao bem comum, à vida humana, à igualdade, à diferença, à construção coletiva e à liberdade.

O exercício dos $\mathrm{DH}$ está diretamente vinculado à dignidade da pessoa humana; e, embora os seres humanos apresentem muitas diferenças entre si, todos carregam em si a igualdade da fragilidade humana por natureza, o que acarreta, por vezes, dor ou sofrimento. Dignidade é algo difícil de definir, mas pode ser compreendida por aqueles que compartilham de valores de sensibilidade humana ou de identificação subjetiva com o outro, simplesmente por ser humano (GENRO, 2014).

Logo no art. $1^{\circ}$, a Declaração Universal dos Direitos Humanos (ORGANIZAÇÃO DAS NAÇÕES UNIDAS, 1948), traz que "Todos os seres humanos nascem livres e iguais em dignidade e em direitos. Dotados de razão e de consciência, devem agir uns para com os 
outros em espírito de fraternidade". Com isso, ganha força a importância de analisar as práticas educativas que orientam a formação de sujeitos de direitos, na ampliação da capacidade de indivíduos e de grupos historicamente excluídos de poder na sociedade, de decidir sobre questões que lhes dizem respeito, bem como os processos de transformação para a construção de sociedades democráticas e humanizadas, além do respeito incondicional.

De acordo com Soriano Diaz (2009, p. 103 apud VALDAMERI, 2018, n.p.), as práticas educativas têm em vista "[...] a educação social para além de solucionar determinados problemas de convivência, e tem uma função não menos importante, que é a de ser um instrumento igualitário e de melhoria da vida social e pessoal", bem como a construção da cultura da tolerância e da paz, no intento do "fortalecimento do ser humano, individual e coletivamente - o que inclui, [...] a capacidade de se indignar e de resistir contra injustiças" (FISCHMANN, 2001, p. 74).

A educação precisa despertar no âmago dos sujeitos a força para que suas atitudes e competências promovam, garantam e protejam seus direitos, pois, conforme Paulo Freire (2001) salienta, a prática educativa é uma dimensão necessária da prática social. Os DH são indissociáveis de uma educação participativa e voltada à democracia. Contudo, o mesmo autor (FREIRE, 2005, p. 94) ressalta que "[...] falar em democracia e silenciar o povo é uma farsa. Falar em humanismo e negar os homens é uma mentira". As práticas pedagógicas atuais postergam o acesso do ser humano à autonomia e o impedem de alcançar sua emancipação intelectual-volitiva e de conquistar sua cidadania intelectual (FORTUNATO, 2019).

O reconhecimento do papel da educação na autodeterminação do povo enquanto sujeito político marca, dentro do pensamento de Freire, sua apresentação como a atividade de base na transformação do mundo (GIMBO, 2017). "O empoderamento do sujeito de direitos e a formação cidadã são eixos estratégicos da educação em Direitos Humanos como forma orientadora de atores individuais e coletivos" (PELLEGRINELLI, 2017, p. 59 apud VALDAMERI, 2019). 
Um aspecto de notória relevância defendido por este estudo é a compreensão de que a educação deve ser voltada para a cidadania como uma das dimensões fundamentais para a luta pela concretização dos $\mathrm{DH}$, o que perpassa por uma consciência clara sobre construção social, dignidade da pessoa humana e justiça social. Uma educação preocupada com a formação humana, desveladora das tramas sociais e compromissada com o bem coletivo pode ser o ponto de partida para lacerar injustiças e intervir nas questões sociais e culturais.

É por meio da educação que o indivíduo tem possibilidade de usar a razão para examinar e refletir acerca do que considera melhor e mais justo (KANT, 1988 apud DIAS, 2018). O esforço educacional deve ser destinado à orientação para o agir prudencial sem que haja o conflito imediato pelas diferenças, com vistas a estabelecer, entre os sujeitos, um convívio harmônico e pacífico, voltado para a defesa e para a construção permanente dos DH (DIAS, 2018; DANELI; AQUINO, 2016).

Nossa sociedade, por sua vez, é marcada por exclusão, desigualdades e injustiças sociais. Por esse motivo, é imprescindível repensar as práticas educativas atuais com o escopo de promover o desenvolvimento integral dos sujeitos, para que estes possam, cada vez mais, lutar pela promoção e pela proteção dos $\mathrm{DH}$ - portanto, mostra-se algo urgente e extremamente necessário. Em conformidade com esse entendimento, Flávia Piovesan (2000, p. 228) ressalta:

[...] A democratização requer o aprofundamento da democracia no cotidiano, por meio do exercício da cidadania e da efetiva apropriação dos direitos humanos. Nesse sentido, não há democracia sem o exercício dos direitos e liberdades fundamentais. A democracia exige o efetivo e pleno exercício dos direitos civis, políticos, sociais, econômicos e culturais. Há, portanto, uma conexão necessária entre democracia e direitos humanos.

Com isso, é delegada à educação a responsabilidade com o desígnio de contribuir para superar a violação dos $\mathrm{DH}$, despertando a consciência de que todos somos sujeitos portadores de direitos, 
estes que devem ser assegurados, protegidos, garantidos e promovidos de forma permanente. A educação de caráter libertador ou emancipador atua como instrumento de emancipação social, comprometido com a universalização de direitos e com a justiça social, conforme frisado por Erasto Fortes Mendonça, na obra de Paulo Freire (2019, p. 31):

[...] a educação numa perspectiva dos direitos humanos será sempre uma resistência neste mundo que se quer transformar, na direção da utopia viável de construção de uma sociedade justa, igualitária e fraterna.

\section{CONSIDERAÇÕES FINAIS}

A partir da leitura crítica do livro O mestre Ignorante: cinco lições sobre a emancipação intelectual, foi possível depreender que Jacques Rancière apresenta a dicotomia existente entre a prática educacional tradicional e o objetivo educacional de formação para reduzir ou abolir as desigualdades sociais e, nessa argumentação, reconhece o princípio explicador como prática nociva tanto para quem ensina como para quem aprende, relacionando-a com o embrutecimento, já que este não permite o desenvolvimento intelectual do indivíduo. Ademais, defende uma proposta fundamentada nos princípios da lógica da provocação/problematização, partindo do princípio da igualdade na capacidade intelectual dos sujeitos como possibilidade de emancipação.

Nessa vertente, a proposta apresentada por Rancière aproxima-se da proposta pedagógica de Paulo Freire, que, mesmo não estando alicerçado no reconhecimento de que todos possuem capacidades intelectuais iguais, aponta para importância de uma prática educativa que provoque no indivíduo "emersão das consciências", percepção do seu papel social e das noções de isonomia, democracia, liberdade, respeito e tolerância, que são questões basilares ao princípio da dignidade da pessoa humana. 
É por meio da educação que os indivíduos podem compreender as forças históricas e as relações de poder que os determinam. Outrossim, somente com uma educação voltada para a emancipação do sujeito é que este consegue ampliar sua visão de mundo, aumentar sua percepção, desenvolver potencial para desafiar o que está dado e constituído, transcender a mera subjetividade e evoluir em novos valores morais, estéticos e intelectuais que permitirão construir uma sociedade mais justa e igualitária.

\section{REFERÊNCIAS}

AQUINO, Julio Groppa (org). Indisciplina na escola: alternativas teóricas e práticas. Org. Julio Groppa Aquino. São Paulo: Summus, 1996, p. 39-55.

BEDIN, G. A. Os direitos do homem e o neoliberalismo. ljuí: Ed. UNIJUÍ, 2002.

BRASIL. Constituição (1988). Constituição Federal. Brasília, DF: Senado Federal: Centro Gráfico, 1988.

BRASIL. Secretaria de Direitos Humanos da Presidência da República. Educação em Direitos Humanos: Diretrizes Nacionais Brasília: Coordenação Geral de Educação em SDH/PR, Direitos Humanos, Secretaria Nacional de Promoção e Defesa dos Direitos Humanos, 2013.

BRETAS, Alex. O mestre Ignorante: como todas as pessoas podem instruir a si mesmas. Blog Medium. [s. I], 16 nov. 2017. Disponível em: https://medium.com/@alexbretas11/o-mestre-ignorante-comotodas-as-pessoas-podem-instruir-a-si-mesmas-225cbf947220. Acesso em: 01 nov. 2019.

CUNHA, Ricarlos Almagro Vitoriano. Fundamentos da mediação em Direitos Humanos. Mediação e Direitos Humanos. São Luis:

Procuradoria Geral de Justiça do Estado do Maranhão/Jornal da Justiça/Cultura, Direito e Sociedade (DGP/CNPqQUFMA). São Luis, p. 123-138, 2014. ISBN: 978-85-98144-43-6. 
DALLARI, Dalmo de Abreu. Direitos humanos e cidadania. São Paulo: Moderna, 1998.

DANELI, Jardel Casanova; AQUINO, Sérgio Ricardo Fernandes de. Qual a educação para os Direitos Humanos? Revista direitos humanos e democracia. Editora Unijuí, ano 4, n. 8, jul./dez 2016. ISSN 2317-5389.

DIAS, Michel Aires de Souza. Rancière e Jacotot: Educar para o dissenso contra a desigualdade. Revista Perspectiva Sociológica, n. 22, p. 19-35, 2018.

FERRARI, Sônia Campaner Miguel. A tese da igualdade das inteligências e a hipótese comunista. Polietica, São Paulo, v. 2, n. 1, p. 49-69, 2014.

FISCHMANN, Roseli. Educação, direitos humanos, tolerância e paz. Paidéia, São Paulo, v. 11, n. 20, p. 67-77, 2001.

FORTUNATO, Izan Rodrigues de Souza. Educação e emancipação na obra o mestre ignorante, de Jacques Rancière. 2019. $106 \mathrm{f}$. Dissertação (Mestrado em Educação) - Universidade Federal do Pará, Belém, 2019.

FREIRE, Paulo. Conscientização: teoria e prática da libertação: uma introdução ao pensamento de Paulo Freire. tradução de Kátia de Mello e silva; revisão técnica de Benedito Eliseu Leite Cintra. - São Paulo: Cortez \& Moraes, 1979.

FREIRE, Paulo. Direitos Humanos e Educação libertadora. Gestão democrática da educação pública de São Paulo/ Paulo Freire; organização e notas de Ana Maria Araújo Freire, Erasto Fortes Mendonça. Rio de Janeiro / São Paulo: Paz e Terra, 2019.

FREIRE, Paulo. Pedagogia do Oprimido. 46. ed. Rio de Janeiro: Paz e Terra. 2005.

FREIRE, Paulo. Política e educação: ensaios/Paulo Freire. 5. ed. São Paulo: Cortez, 2001. v. 23 (Coleção Questões de Nossa Época)

GADOTTI, M. Educação contra a educação. Rio de Janeiro: Paz e Terra. 1981. 
GENRO, Maria Elly Herz; ZITKOSKI, Jaime José. Educação e direitos humanos numa perspectiva intercultural. Revista da FAEEBA Educação e Contemporaneidade, Salvador, v. 23, n. 41, p. 237-245, jan./jun. 2014.

GIMBO, Fernando. Emancipação intelectual e democracia: para uma filosofia crítica da educação a partir de Jacques Rancière e Paulo Freire. Griot: Revista de Filosofia, Amargosa, Bahia, v. 16, n. 2, p. 270-284, dez. 2017.

HIDALGO, Kênia Ribeiro da Silva; ZANATTA, Beatriz Aparecida; FREITAS, Raquel Aparecida Marra da Madeira. A pedagogia da explicação, a pedagogia da emancipação intelectual e o princípio da liberdade. Práxis Educacional, v. 11, n. 20, Vitória da Conquista. p. 333-348. set./dez. 2015.

MAGENDZO, A. K. Propuesta Haciael nunca más desde la Educación en Derechos Humanos. Programa Interdisciplinario de Investigaciones en Educación- PIIE. Academia de Humanismo Cristiano, Santiago, 2002.

MAGRI, Cledir Assísio. A educação em direitos humanos: uma abordagem a partir de Paulo Freire. REP - Revista Espaço Pedagógico, Passo Fundo, v. 19, n. 1, p. 44-63, jan./jun. 2012.

MULINARI, Filicio; MUNIZ, Vinícius Arena. Da educação, do senso comum e do saber filosófico: uma proposta pedagógica a partir de Rancière. Educação em Debate, Fortaleza, ano 40, n. 77, set./dez. 2018.

ORGANIZAÇÃO DAS NAÇÕES UNIDAS. Declaração Universal dos Direitos Humanos. 1948. Disponível em:

https://brasil.un.org/sites/default/files/2020-09/por.pdf. Acesso em: 12 mar. 2020.

PIOVESAN, Flávia. Direitos Humanos, Democracia e integração regional: Os desafios da globalização. Revista da procuradoria Geral do Estado de São Paulo, São Paulo, n. 54, p. 221-247, dez. 2000.

PIRES, Diego Bruno de Souza. Judicialização da educação no Brasil: tendências da produção do conhecimento e perspectivas 
para a exequibilidade do direito (2000-2010). 2017. $113 \mathrm{f}$.

Dissertação (Mestrado em Educação) - Programa de pós-graduação em educação departamento de educação. Universidade Estadual de Feira de Santana. Feira de Santana-BA. 2017.

RANCIÈRE, Jacques. $\mathbf{O}$ mestre ignorante: cinco lições sobre a emancipação intelectual. 3. ed. Trad. Lílian do Valle. Belo Horizonte: Autêntica, 2018.

RODRIGUES, Paula Izabela Nogueira Bartkiw. O mestre ignorante e o processo da experiência e do conhecimento. Revista Eco Pós, Rio de Janeiro, Cinema Experimental, v.19, n. 2, P. 260-265, 2016, ISNN 2175-8889. Resenha.

SANTOS, Milton. Por uma outra globalização: do pensamento único à consciência universal. 3. ed. Rio de Janeiro: Record, 2000. TRÓPIA, Guilerme; PINTO NETO, Pedro da Cunha. Produções artístico-culturais com educação em ciências: embrutecimento ou emancipação intelectual? Enseñanza de lasciencias, Sevilla, n. extraordinário, p. 5047-5051, 2017. ISSN (digital): 2174-6486.

VALDAMERI, Daiane Soares. Direitos humanos e educação: a construção de uma cultura democrática. Jus, maio 2018. Disponível em: https://jus.com.br/artigos/66343/direitos-humanos-e-educacao. Acesso em: 30 set. 2019.

VERMEREN, Patrice; CORNU, Laurence; BENVENUTO, Andrea. Atualidade de o mestre ignorante. Educ. Soc. Campinas, v. 24, n. 82, p. 185-202, 2003.

Submetiido em: Julho/ 2020. Aceito em: Dezembro/ 2020. 
